\section{Information processing and strategy}

\author{
MARI A. PETERSON, Cornell University, Ithaca, N.Y. 14850 \\ and \\ REIN PETERSON, Columbia University, New York, N.Y. 10027
}

A replication of Neisser's visual scanning experiment was successfully carried out. An attempt to control for difficulty of target letters in relation to one another, as well as to the background letters, was only partially successful. Several strategies of scanning different conditions were reported during debriefing of Ss.

In several studies (Neisser, 1963, 1964; Neisser, Novik, \& Lazar, 1963), Neisser has gathered data to support his contention that when a high degree of accuracy is not required, many subsystems for processing visual information can operate in parallel. In each experiment $\mathrm{Ss}$ were asked to identify a target symbol or symbols (letters and numbers) by scanning down a printed list of background symbols in which a target (letter) was embedded. After 12 consecutive experimental days, Neisser found that the time required to identify any of several target symbols became approximately equal to the time required to identify only a single target symbol from the list.

Our experiment was designed to evaluate the effect of controlling for the relative difficulty of the target letters selected, something Neisser did not do in his experiments. By not controlling for difficulty, it is possible for the experimental results to be corfounded. METHOD AND PROCEDURE

For a discussion of the basic

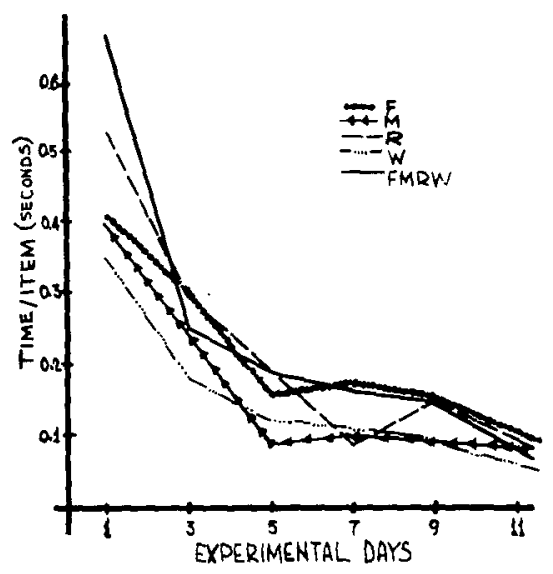

Fig. 1. Time-per-item as a function of day of practice. methodology, we refer readers to Neisser's (1963) article. We will discuss only aspects of our design that differ somewhat from his. In order to control for difficulty of letters, the experimental letters were chosen using a confusion matrix compiled by Gibson et al (1967). According to their confusion matrix, each of the letters $F, M$, $R$, and $W$ (our target letters) were confused with any of the letters $E, K, N, P, V$, and $Y$ (our background letters) approximately the same number of times. The target letters were almost never confused with each other, with the exception of $M$ and $W$, which were confused on occasion. As a result, in our experiment the two letters $M$ and $W$ were never presented at the same time. The chosen letters were then compiled into lists in a manner that was similar to the one used by Neisser.

Each list consisted of a single column of 50 items, and each item was a string of six letters. Of these, 49 items were random permutations of the six background letters $(E, K, N, P, V, Y)$. One of the 50 items was selected randomly to contain the target letter. The target letter was also randomly placed in one of the six spaces in the line. There were five conditions in the experiment, one for each of the target letters and one where any one of the four target letters could occur with equal probability. For each of the five conditions, 30 lists were printed by an IBM 407 printer and pasted onto heavy cardboard for insertion into a custom-built scanning box.

The experiment lasted 12 experimental days. On each day the $\mathrm{Ss}$ scanned a minimum of 15 lists for each condition. The order of conditions was varied Table 1

Average Errors Per Day in Each Condition

\begin{tabular}{ccccc}
\hline $\mathrm{F}$ & $\mathrm{M}$ & $\begin{array}{c}\text { Condition } \\
\mathrm{R}\end{array}$ & $\mathrm{W}$ & FMRW \\
\hline 2.78 & 1.72 & 3.64 & 1.00 & 3.10 \\
\hline
\end{tabular}

randomly from day to day. Ss were instructed to aim for both speed and accuracy while scanning down the list for a target letter.

The Ss were three male $\mathrm{PhD}$ candidates (in business administration, ancient history, and classics). Each $\mathrm{S}$ was run individually for 12 days, and keen competition for fastest reaction time (i.e., when the target letter occurred in the first few rows), as well as overall average length of scan time for each target, developed among the Ss. In the single-target condition Ss scanned for $F, M, R$, and $W$ separately, with $100 \%$ probability of occurring, whereas in the multiple-target condition (4), they scanned the list for F, M, R, or W, each having a $25 \%$ probability of occurring. RESULTS AND DISCUSSION

The data were analyzed in terms of average time per item as a function of day of practice, averaged over all the three Ss. The 15 search times were plotted against position of the target item, and a linear line was fitted by the method of least squares to determine the slope.

Figure 1 shows how the mean time per item changed over 12 days in each of the five conditions. Our results appear to replicate those of Neisser with regard to time per item and the convergence of the five conditions by Day 12 . Also, our error rates (see Table 1) compare favorably with the Neisser et al (1963) experiment for three conditions (F, R, and 4 ). For $M$ and $W$ our error rate was somewhat lower, indicating that we were only partially successful in designing an experiment with equally difficult letters. The Ss pointed out during the experiment that the $F$ and $R$ were much more easily confused with the background letters $E$ and $P$ than $W$ and $M$ were with $V$ and $N$. In the same vein, $S$ s commented that $M$ and $W$ were easily discerned because they looked wider than any of the other letters.

Ss also reported using two kinds of strategy: different speeds for different conditions and choosing to ignore certain features of the stimulus. One $S$ claimed that toward the end of the experiment he had "stopped thinking and started reacting," looking only for a letter that was different from the ones in the background. REFERENCES

GIBSON, E. J., OSSER, H., SHIFF, W., \& SMITH, J. An analysis of critical features of letters tested by a confusion matrix. Mimeographed copy, Cornell University, 1967.

NEISSER, U. Decision time without reaction time: Experiments in visual scanning. American Journal of Psychology, 1963, 76, 321-329.

NEISSER, U. Visual search. Scientific American, 1964, 210, 94-102.

NEISSER, U., NOVIK, R., \& LAZAR, R. Searching for ten targets simultaneously. Perceptual \& Motor Skills, 1963, 17, 955-961. 